\title{
Custodia compartida: atribución vivienda familiar Shared custody: the acquisition the family living
}

\author{
Beatriz Escudero Berzal* \\ *bmesudero@gmail.com
}

\begin{abstract}
Abstrac:
When there is a marital or partnership conflict and children are involved, the main problem is to resolve the children's custody followed by the settlement of financial matter. Our Judical Ordinance allows that opposing parties reach an agreement openly always looking for the minor's best interest. The later which is the most important issue beyond anything else. The acquisition of child custody usually bestowed by the mother, produces an automatic orbitration utilized for the family living.

However, our society is quickly changing as is the family structure. Before sole custody is declared according to our. Ordenance, the 2005 Civil Code introduced shared custody.

This essay wants to be a sample of the present lack of regulation in our legislation to regulate one of the main economic effects that causes joint custody as for example the conferral of the use of the family home, and the need for regulation especially in a context of economic crisis like the current one, in which joint custody and family living between parents force the extinct family unit to mantain excessive expenditures which are required for a parent during the period they do not have custody as the need of a house. In addition to other members of the family who reside with the minor, a common family living quarter, also which the problem of space to resolve internal family problems which can jeabordize the family's good relationship.
\end{abstract}

Keywords: Shared custody, The family living, Children, Divorce

\section{Resumen:}

Cuando se produce una crisis matrimonial o de pareja y existen hijos a su cargo, el principal problema es el de atribución de la custodia del menor o menores y seguidamente la disposición de los efectos económicos que esa ruptura produce. Nuestro Ordenamiento Jurídico permite que sean las partes en conflicto las que acuerden libremente su régimen, siempre que quede salvaguardado el interés del menor, como un interés superior digno de protección por encima de los demás. La atribución de la custodia del menor o menores a uno de los progenitores, normalmente la madre, produce la atribución automática del uso de la vivienda familiar.

Pero nuestra sociedad está cambiando rápidamente y el modelo de familia también. Y ante la custodia exclusiva imperante en nuestro Ordenamiento, la reforma de nuestro Código Civil en el año 2005, introdujo la custodia compartida. 
Este artículo quiere mostrar el vacío normativo existente en nuestra legislación para regular uno de los principales efectos económicos que produce la custodia compartida, como es el de la atribución del uso de la vivienda familiar. Y la necesidad de su regulación, sobre todo en un contexto de crisis económica como el actual, en el que al ser compartida la custodia y por tanto la vivienda familiar entre los progenitores, obliga a la extinta unidad familiar a mantener unos gastos tal vez excesivos, como los que conllevan la necesidad de una vivienda para cada progenitor en los periodos en los que no ostentan la custodia compartida, además de los propios de la vivienda familiar en la que residen los menores; así como los problemas propios de gestionar un espacio común en unas situaciones que normalmente no se caracterizan por las buena relaciones entre los progenitores que acaban de poner fin a su relación a través de un proceso contencioso.

Palabras clave: Custodia Compartida, Vivienda Familiar, Menor, Divorcio

\section{Article info:}

Received: 30/04/2013 / Received in revised form: 20/06/2013

Aceppted: 01/07/2013 / Published online: 15/07/2013

DOI: http://dx.doi.org/10.5944/comunitania.6.2

\section{Introducción}

Cuando dos personas deciden poner fin a su relación matrimonial o de pareja, hay que decidir sobre todos los efectos que una vida en común han producido. Lo primero y principal, son los hijos, si los hubiera. Todo lo demás es secundario. La verdad, más que secundario, es que vendrá determinado por cómo se ordene o se determine la relación con éstos.

La atribución de la custodia a uno sólo de los progenitores, prácticamente siempre la madre, ha sido lo habitual hasta ahora. Pero es cierto, que respecto lo que antes era normal, ahora no lo es. Nuestra sociedad ha avanzado y el protagonismo que ha ido reivindicando el padre dentro de la familia, implicándose, en las tareas domésticas y corresponsabilizándose en el cuidado de los hijos, es ya una realidad. También la incorporación de la mujer al mercado laboral, su participación activa y sus nuevas aspiraciones de igualdad en los terrenos laborales y económicos(Alberdi y Escario 2007).Esto hace que la realidad social que se plantea en los casos de separación y divorcio sea muy distinta a la que tuvo en cuenta el legislador en su primera regulación.La igualdad de géneros, la igualdad de derechos que propugna nuestra Constitución es una realidad constante. Reclamándose esta igualdad cuando se trata de ordenar el cuidado de los hijos al ponerse fin a una relación. 
La introducción en el CC hace 8 años, con la Ley 15/2005' ,de la posibilidad de la custodia compartida, supeditada siempre al mutuo acuerdo de ambos progenitores, o con carácter excepcional a instancia de una de las partes con informe favorable del Ministerio Fiscal, supuso un avance en cuanto a su reconocimiento legal, pero adolece de importantes carencias en cuestiones fundamentales. A saber, no formula una definición conceptual, ni realiza un análisis estructurado del modelo de guarda y tampoco aborda medidas intrínsecamente unidas a su adopción, como son la atribución de la vivienda y las pensiones alimenticias a favor de los hijos, cuya regulación no ha sido modificada.

El artículo 96 del Código Civil(Ley 30/1981)² por la que se modifica la regulación del matrimonio en el Código Civil y se determina el procedimiento a seguir en las causas de nulidad, separación y divorcio) regula a quien debe serle atribuido el uso de la vivienda conyugal sea propiedad de uno de los cónyuges o de ambos. El uso de la vivienda familiar a favor de los hijos menores hace que sea el progenitor custodio, normalmente la madre, quien se quede con el uso de la vivienda, al menos hasta que los hijos menores alcancen la mayoría de edad. ¿Pero qué ocurre cuando la custodia se atribuye a ambos progenitores?

La adjudicación de la vivienda a favor de uno u otro cónyuge, presenta en la actualidad uno de los principales motivos de controversia entre ambos cónyuges por los siguientes motivos: la mayoría de las viviendas en la actualidad, se encuentran sujetas a hipotecas; además, los precios que los inmuebles tienen, bien sean arrendados o bien comprados, son bastantes elevados. El hecho de que se atribuya a uno de los cónyuges el uso de la vivienda supone respecto del cónyuge obligado a abandonar el domicilio familiar, una doble carga económica (con independencia de otras cuestiones que no son objeto de este artículo como el pago de pensión compensatoria, etc.), ya que éste tendrá que pagar la renta o compra de otro inmueble donde vivir junto con el abono de la mitad de la hipoteca del que fue el domicilio conyugal. Lo que sin duda le colocará en una situación económica peor. Esto hace, sin lugar a duda, que una de las controversias más importantes que se plantean entre los cónyuges en el momento de la disolución del vínculo, matrimonial o no, sea el de conseguir que judicialmente se le atribuya el uso de la vivienda conyugal. Y esto puede llevar, no muy afortunadamente, a que en muchos procesos matrimoniales contenciosos, cada parte reclame para sí la guarda y custodia de los menores, con la intención encubierta de conseguir el uso exclusivo de la vivienda familiar, teniendo así una carga económica menor.

Siendo, sin lugar a dudas, la regulación dada en el párrafo primero del artículo 96 del Código Civil (Ley 30/1981), que establece la atribución automática por parte del Juez, en defecto de acuerdo de las partes, del uso de la vivienda familiar y de los

\footnotetext{
1 Ley 15/2005, de 8 de julio, por la que se modifican el Código Civil y la Ley de Enjuiciamiento Civil en materia de separación y divorcio

2 Redactado por la Ley 30/1981, del 7 de julio (BOE del 20 de julio).
} 
objetos de uso ordinario en ella, a los hijos y al cónyuge en cuya compañía queden, un gran impedimento para la posibilidad de llegar a acuerdos a favor de la guarda y custodia compartida por parte del cónyuge que cree que tiene más posibilidades, por sus circunstancias, para ser el titular de la custodia exclusiva. Pero también, está ocurriendo el caso contrario. Esto es, la insistencia del otro progenitor a pedir custodia compartida o conjunta, movido más por intereses económicos que realmente por mantener un contacto permanente con los menores.

Volvemos así al inicio de este apartado, la controversia sobre la atribución del derecho de uso de la vivienda condiciona por completo las demás pretensiones de las partes. El conseguir la guardia y custodia de los hijos de forma exclusiva determina conseguir con nuestra legislación actual, el uso exclusivo de la vivienda.

\section{Evolución de la familia. Nuevas situaciones, nuevas demandas}

Familia y sociedad están sufriendo transformaciones constantes y muy rápidas en los últimos tiempos. Cambios trascendentales en lo relativo a la familia y sociedad española a lo largo de los más de treinta años desde el final de la Dictadura, la Transición y la normalización democrática que finaliza con la internacionalización de España (Del Fresno 2011). Los nuevos modelos de familia que se han desarrollado en los últimos años exigen soluciones muy distintas en caso de ruptura de los cónyuges, a las adoptadas para las familias tradicionales.

La familia, según la Declaración Universal de los Derechos Humanos (1948), "es el elemento natural, universal y fundamental de la sociedad, y tiene derecho a la protección de la sociedad y del Estado». Los lazos que definen una familia son de dos tipos: vínculos de afinidad derivados de un vínculo reconocido socialmente (como el matrimonio), y vínculos de consanguinidad (como la filiación entre padres e hijos o los lazos entre hermanos).

No hay consenso sobre la definición de la familia. Las distintas definiciones van a depender del campo de la ciencia que se escoja.Así, para la sociología, la familia es una agrupación por parentesco que se encarga de satisfacer las necesidades humanas del grupo. Para la economía, la familia es una unidad de producción o de consumo.Y a nivel jurídico, la familia está definida por un vínculo legal, el matrimonio, el registro como pareja de hecho, la adopción, etcétera.

La familia, como cualquier otra institución social es sensible a los cambios que tienen lugar en su entorno cultural e histórico y se adapta a ellos (Menendez Álvarez-

3 Declaración Universal de Derechos Humanos. Resolución Asamblea General 217 A (III) del 10/12/1948. Art. 16, párrafo 3. 
Dardet 2011). En 1900 España era un país bastante pobre, con altos niveles de mortandad y de fecundidad y un país eminentemente rural (más del $60 \%$ de la población vivía en el campo) (Reher 2004) mientras que a final del siglo, se transformó en una sociedad urbana, con una sociedad con alto nivel de educación, de consumo. Los grandes cambios del siglo pasado transformaron la familia rural y agrícola en urbana e industrial. Transformando también las funciones que tenían asignados cada uno de sus miembros. No se trata de una crisis de familia sino, a decir de Flaquer, de una segunda transición histórica de la familia (Flaquer 1991, 1998).

La familia tradicional actuaba como una unidad productiva. Integrada por el padre y la madre, unidos por vínculo de matrimonio bien religioso o legal, y los hijos. Era patriarcal, el cabeza de familia era el padre mientras que la madre quedaba relegada a ocuparse de las tareas del hogar y de cuidado de los hijos, ya que en raras ocasiones trabajaba fuera del hogar. Sus miembros dependían de la familia para su subsistencia, educación y protección. Sólo la muerte era capaz de romper o acabar con el núcleo familiar, ya que no existía el divorcio.Este modelo de familia tradicional se está perdiendo cada vez más. Nos encontramos ahora con otro distinto, que es el de la familia moderna. Las uniones entre personas son distintas y también el rol que desempeña cada persona en la familia ha cambiado en los últimos años.

Así, en la familia moderna, la mujer comienza a realizar trabajos remunerados fuera del hogar y, paralelamente, desciende el número de hijos. La estructura de esta familia, también es distinta. Hay familias con un solo progenitor, parejas sin vínculo religioso ni legal, etc. Hay independencia en las relaciones, independencia económica e independencia en la residencia. La familia en España también ha experimentado ese cambio vertiginoso que se aprecia en la nupcialidad, la cohabitación, la edad del matrimonio, la forma del matrimonio, la emancipación familiar, los nacidos de madres no casadas, el divorcio, las segundas nupcias, el tamaño de los hogares (Iglesias de Ussel 2005). También estas familias modernas se distinguen por el modo en que pueden disolverse: por separación, divorcio, nulidad o fallecimiento. La última causa, no va a ser motivo de análisis en este momento. Vamos a analizar la evolución del divorcio y separación en nuestro país, así como la evolución de los efectos que la ruptura entre cónyuges, produce en la unidad familiar.

En 1981, 45 años después de que se derogase la primera Ley del Divorcio en España (25 de febrero de 1932), nuestro país volvía a admitir de forma legal el fin de los matrimonios, admitiéndose de forma legal el fin de los matrimonios siempre que se demostrase el cese efectivo de la convivencia entre las partes o la violación grave o reiterada de los deberes conyugales y hubiera habido previamente un dilatado periodo de separación según dictaba nuestro Código Civil.

En 2005 se modificó el Código Civil y la Ley de Enjuiciamiento Civil en materia de separación y divorcio con la comúnmente llamada Ley del Divorcio Exprés, (L 15/2005 de 8 de Julio). Las modificaciones más destacadas son: las relativas a los 
plazos para divorciarse, sobre todo, a la modificación relativa a que ya no era necesario separarse con anterioridad para divorciarse; la unilateralidad y por último, la no necesidad de alegar concurrencia de causa alguna.

Desde 1981 hasta hoy, las rupturas matrimoniales han tenido un ascenso constante, y ello se debe principalmente al cambio de modelo familiar que se produce como consecuencia de la aparición de comportamientos familiares distintos. Aumentó la incorporación de la mujer al ámbito laboral, creció el número de mujeres que accedían a la enseñanza universitaria, el nivel de instrucción femenino se elevó, y a su vez, la tasa de natalidad disminuyó, el número de hijos por mujer también se redujo, al igual que aumentó el número de matrimonios sin hijos. La incorporación de la mujer al ámbito laboral como su mayor nivel de preparación, son determinantes de la llamada liberación de la mujer. Todo ello además proporciona una seguridad vital a la mujer, la no dependencia respecto de su esposo, la posibilidad de tener su propio desarrollo personal y profesional fuera del ámbito familiar y a su vez, produce un detrimento de la capacidad de control ejercida durante mucho tiempo por el hombre sobre su mujer, contribuyendo sin duda, a que surja una mayor conflictividad matrimonial, hasta esa época impensable (Aguilera Arilla y González Yanci 2003).

Los datos publicados desde 1981 al 2000 determinan en cifras absolutas, que se pasa de 16.362 rupturas matrimoniales en 1981 a 102.403 en el año 2000 (Carreras y Taforell 2005). Entre el año 2002 a 2012 pasamos de 105.534 a 110.651 disoluciones matrimoniales (gráfico 1)). Las rupturas matrimoniales aumentaron un $0,3 \%$ con respecto al año anterior. En el momento de crisis económica que nos encontramos, muchas parejas prefieren sobrellevar la convivencia antes que iniciar un proceso judicial de disolución. Es indudable que los costes económicos que suponen las medidas que de él se derivan como el mantenimiento de dos viviendas y la duplicidad de gastos en caso de separación, hacen que muchos matrimonios o parejas no puedan planteárselo. 


\section{GrÁFICO 1. Disoluciones matrimoniales 2002-2011}

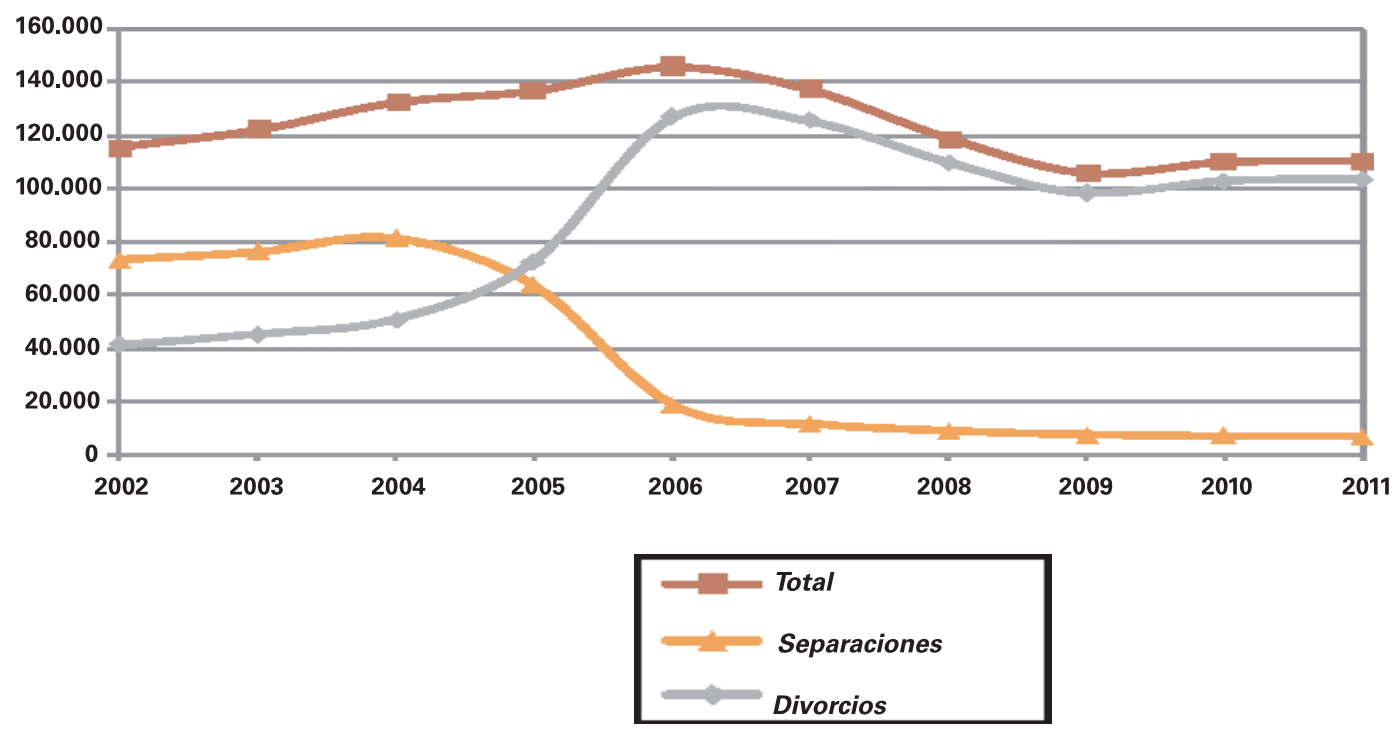

Fuente: (INE 2012.

En el momento de crisis económica que nos encontramos, muchas parejas prefieren sobrellevar la convivencia antes que iniciar un proceso judicial de disolución, un $24 \%$ menos de divorcios que antes de la crisis (El Huffington Post 2012 ). Es indudable que los costes económicos que suponen las medidas que de él se derivan como el mantenimiento de dos viviendas y la duplicidad de gastos en caso de separación, hacen que muchos matrimonios o parejas no puedan planteárselo.

\section{Principales efectos de la ruptura matrimonial}

\subsection{La custodia}

En todo proceso de nulidad, separación o divorcio, la primera medida que debe adoptarse es la atribución de la guarda y custodia de los hijos, es decir, determinar con quien van a quedar, y fijar un régimen de visitas para el otro progenitor(Alascio y Marín 2007). Existen tres tipos de custodia(Catalán Frías 2011): A) Custodia exclusiva, a favor de uno de los progenitores. Es la más frecuente, y la adoptan los Tribunales cuando no hay mutuo acuerdo. B) Custodia repartida o alterna, cuando cada uno de los progenitores pueden tener a los hijos durante un periodo de tiempo del año. C) Custodia compartida o conjunta, definida como la conjunción de custodia legal o física de los hijos por ambos progenitores, de manera que se asegura el acceso continuado y frecuente de los hijos a ambos. 
Hay que recordar, que todo el conjunto normativo que existe en torno a la figura de la guarda y custodia tiene su punto de partida en el artículo 39 de la Constitución Española (Ivars Ruiz 2007).La Ley 30/81, del 7 de julio (BOE del 20 de julio), por la que se modifica la regulación del matrimonio en el Código Civil, no hacía referencia alguna a la guarda y custodia compartida ya que se refería únicamente a la posibilidad de la guarda y custodia exclusiva de uno de los progenitores e, incluso, de una tercera persona. Fue la Ley 15/2005, de 8 de julio, que modificó el Código Civil y la Ley de Enjuiciamiento Civil en materia de separación y divorcio (BOE, número 163, de 9 de julio), la que introdujo la posibilidad de acordar la guarda y custodia compartida de los hijos menores (previsto en el artículo 92 del Código Civil). La Ley permite la custodia compartida cuando es acordada por ambos progenitores por voluntad propia (artículo 92.5 del Código Civil).

Es razonable pensar, que generalmente(Alascio 2011), cuando los padres, titulares de la patria potestad, están de acuerdo en la modalidad de custodia escogida, ésta será la decisión más favorable para todas las partes implicadas, y en particular beneficiará el interés de los hijos, que es el pilar fundamental sobre el que deben apoyarse todas las decisiones con respecto a ellos, ya sean tomadas por los padres como por la autoridad judicial.De manera excepcional, podrá el Juez adoptar la medida de custodia compartida, cuando lo solicite una sola de las partes, siempre con informe favorable del Ministerio Fiscal y quedando probado que ésta es la única forma de proteger adecuadamente el interés superior del menor, como dispone el artículo 92.8 del Código Civil en su redacción dada por Ley $15 / 2005$.

De lo anterior se desprende el carácter excepcional que tiene en nuestro Ordenamiento la medida de la custodia compartida, y que nuestra legislación no se ha adaptado íntegramente a la transformación que ha tenido la sociedad y la familia española y a los nuevos roles asumidos por hombres y mujeres. Una muestra de ello es el siguiente cuadro, en el que se aprecia claramente que hoy la custodia se sigue otorgando de forma preferente a la madre en detrimento de la custodia compartida. 


\section{CuAdro 1. Atribución de la custodia según la modalidad de término del matrimonio}

\section{DIVORCIOS}

\begin{tabular}{|r|r|r|r|r|r|r|}
\hline & TOTAL & Padre & Madre & Ambos & Otros & \multicolumn{2}{|c|}{ No procede } \\
\hline \hline 2011 & 103.290 & 2.961 & 44.887 & 6.729 & 400 & 48.313 \\
\hline \hline 2010 & 102.690 & 3.076 & 45.284 & 5.695 & 356 & 48.279 \\
\hline \hline 2009 & 98.207 & 2.918 & 44.048 & 5.046 & 377 & 45.818 \\
\hline 2008 & 109.922 & 2.444 & 50.800 & 5.716 & 178 & 50.784 \\
\hline 2007 & 125.721 & 3.113 & 55.630 & 6.249 & ---- & 60.729 \\
\hline
\end{tabular}

\section{SEPARACIONES}

\begin{tabular}{|c|c|c|c|c|c|c|}
\hline & TOTAL & Padre & Madre & Ambos & Otros & No procede \\
\hline 2011 & 6.911 & 167 & 3.107 & 491 & 13 & 3.133 \\
\hline 2010 & 7246 & 246 & 3544 & 435 & 17 & 3.004 \\
\hline 2009 & 7674 & 2349 & 3714 & 469 & 18 & 3.224 \\
\hline 2008 & 8.759 & 161 & 4.298 & 485 & 11 & 3.804 \\
\hline 2007 & 11.581 & 284 & 5.455 & 709 & ----- & 5.133 \\
\hline
\end{tabular}

\section{NULIDADES}

\begin{tabular}{|c|c|c|c|c|c|c|}
\hline & Total & Padre & Madre & Ambos & Otros & No procede \\
\hline 2011 & 2 & 5 & 14 & 5 & 0 & 107 \\
\hline 2010 & 140 & 5 & 25 & 8 & 0 & 140 \\
\hline 2009 & 127 & 6 & 12 & 0 & ------- & 109 \\
\hline 2008 & 142 & 5 & 9 & 5 & -------- & 123 \\
\hline 2007 & 149 & 4 & 28 & --------- & -------- & 117 \\
\hline
\end{tabular}

Fuente: INE 2012. 
En 2012, los Juzgados españoles registraron más de 127.000 separaciones, y en el $81 \%$ de los casos se concedió la custodia de los menores a las madres, mientras que sólo un $12 \%$ de las custodias son compartidas (INE 2012). Esto ocurre así, porque en nuestro ordenamiento, como hemos visto, sólo se concede la custodia compartida cuando hay acuerdo entre las partes, entendiéndose que sólo cuando hay una relación de avenencia entre los progenitores se podrá garantizar el adecuado desenvolvimiento de la medida en beneficio de los menores siendo inadecuada en los casos de conflicto entre los progenitores.

Pero mientras este carácter excepcional es lo que se da en la legislación nacional, con posterioridad, en las legislaciones autonómicas que han regulado esta figura el tratamiento es diverso. Por un lado, la ley aragonesa de custodia compartida (Ley 2/2010, de 26 de mayo, de igualdad en las relaciones familiares ante la ruptura de convivencia de los padres, publicada en el BOA de 8 de junio de 2010), establece la custodia compartida preferente en caso de separación o divorcio contencioso. En el mismo sentido la legislación valenciana (Ley 5/2011, de 1 de abril. de la Generalitat, de relaciones familiares de los hijos e hijas cuyos progenitores no conviven, publicada en el BOE de 25 de abril de 2011). Sin embargo, en Cataluña, (Ley 25/2019, de 29 de julio, del libro segundo del Código Civil de Cataluña, relativo a la persona y la familia, publicada en el BOE de 21 de agosto de 2010) y en Navarra, (Ley Foral 3/2011, de 17 de marzo, sobre custodia de los hijos en los casos de ruptura de la convivencia de los padres, publicada en el BOE de12 de abril de 2011) la custodia compartida no es el criterio preferente, sino que se deja a criterio del Juez y siempre que se den unos requisitos.

Existe como vemos, una dispersa regulación en esta cuestión, que puede y que de hecho está produciendo desigualdades de trato ante la misma situación, dependiendo del territorio nacional en que te encuentres, siendo por tanto contrario al principio de igualdad (artículo 14 de la Constitución Española).La Asociación de Mujeres de Juristas Themis(Gonzalo Valgañón 2011), ya ha alertado sobre laposibilidad de que las leyes aragonesa y valencianas anteriormente citadas, puedan ser inconstitucionales, ya que modifican profundamente los artículos 92 y 96 del Código Civil para esas Comunidades, en base a que conforme al artículo 149, 1.8 de la Constitución Española no es competencia de las Comunidades Autónomas modificar el Código Civil. Pueden modificar, desarrollar o revisar, pero no crear ex novo.

Parece que es realmente necesaria una reforma del Código Civil para así, para coordinar todo el territorio nacional. En este sentido, diversas asociaciones de padres y madres separados, asociación de abuelos separados, han presentado con fecha 8 de mayo de 2013 una Iniciativa Legislativa Popular (ILP) en el Congreso de los Diputados ${ }^{4}$, que pretende modificar algunos artículos del Código Civil para que

4 ILP relativa a la Proposición de Ley de modificación del Código Civil para la extensión a todo el territorio de Estado español de las diferentes normativas forales y autonómicas reguladoras de las relaciones 
«el juez como regla general, atribuya a ambos progenitores, de manera compartida, el régimen de convivencia con los hijos e hijas menores de edad, sin que sea obstáculo para ello la oposición de uno de los progenitores que pretenda obtener la custodia individual, o las malas relaciones entre ellos".

Esta Iniciativa Legislativa Popular, lo que pretende es que a falta de acuerdo entre los progenitores, lo quieran o no, tendrán que compartir la custodia de los hijos. Ha sido admitida a trámite por la Mesa del Congreso ${ }^{5}$.Y será necesario que se recojan 500.000 firmas en el plazo de seis meses para que pueda ser discutida en el Congreso de los Diputados, pudiendo, prorrogarse otros tres meses más si la Mesa considera que se dan causas mayores. Caducando la ILP si no se recogen las firmas requeridas ${ }^{6}$.

Además, ya ha sido anunciada por el Ministerio de Justicia del Gobierno de España la reforma del Código Civil para equiparar por Ley la custodia compartida y la monoparental en los casos de separación o divorcio, eliminando así la excepcionalidad, de la custodia compartida ${ }^{7}$. La reforma anunciada por el Gobierno y que se presentará en los próximos meses, va encaminada a otorgar al Juez las facultades necesarias para determinar, siempre actuando en interés de los menores, en cada caso concreto, atendiendo a los presupuestos materiales concurrentes en cada uno de ellos, y dentro de las distintas posibilidades de convivencia y estancia de estos con sus padres, en los supuestos de ruptura de la unidad familiar, cuál de ellas es aquella que más y mejor les favorece. Se trata en definitiva, de otorgar amplia libertad al Juez para que, analizados todos los informes, determine qué es lo mejor para el interés del menor, por encima del interés de los padres(Quilez 2013).

A este debate, se ha añadido la última y reciente Sentencia del Tribunal Supremo de 29 de abril de 2013, que se pronuncia a favor de la custodia compartida siempre que lo pida uno de los progenitores(STS 257/2013) ${ }^{8}$. La Sala Primera del Tribunal Supremo ha fijado doctrina en torno a la interpretación de los apartados 5,6 y 7 del artículo 92 del Código Civil en lo relativo a los presupuestos que han de concurrir y valorarse para que pueda adoptarse en interés del menor, el régimen de guardia y custodia compartida. EITribunal Supremo no considera excepcional el régimen de custodia compartida sino como la regla general y siendo impuesto por el Juez sin

de los progenitores con sus descendientes comunes en caso de ruptura de la convivencia, medie o no relación conyugal).

5 Acuerdo de la Mesa del Congreso de los Diputados de 14 de mayo de 2013.

6 Articulo 87.3 y siguientes de la Constitución Española 1978 y Ley Orgánica 3/1984, de 26 de Marzo, Reguladora de la Iniciativa Legislativa Popular, y Modificada P.Ley orgánica 4/2006, de 26 de Mayo.

7 Diario de Sesiones Congreso de los Diputados (DS). Comisiones.n 25 de 25/01/2012.

8 STS (Sala de lo Civil, sección Primera)sentencia número 257/2013 de 29 de abril. Ponente: Excmo. Sr. D. José Antonio Seijas Quintana). 
necesidad de informe fiscal que lo avale, fundado siempre en el interés del menor afectado y no en el de los padres(TS 2013) ${ }^{9(12)}$.

Como puede comprobarse el tema suscita polémica. $Y$ habrá que esperar a la anunciada reforma legislativa que se producirá sin lugar a duda en la presente Legislatura.

\subsection{Adjudicación del uso de la vivienda familiar}

Como se señaló al principio, en los supuestos de ruptura matrimonial, una de las cuestiones en litigio en los procesos contenciosos es el de la adjudicación del uso de la vivienda familiar. No pudiendo perderse de vista que la guarda y custodia de los hijos ha constituido la llave para conseguir la atribución de la vivienda conyugal y las prestaciones de alimentos. Por lo que podemos decir, que el efecto económico más trascendente de la atribución de la custodia de los hijos es el correlativo al derecho al uso de la vivienda familiar, que en nuestro Código Civil es de atribución automática al progenitor custodio (artículo 96)(Alascio y Marín 2007). Pudiendo Ilegar en algunos casos, a la nada deseable, pero existente situación, de peticiones de guarda y custodia compartida disfrazadas, que en la realidad persiguen intereses patrimoniales (Marín García de Leonardo 2009).

El régimen jurídico de la vivienda familiar en los casos de crisis matrimonial viene recogido en los artículos 90, 91, 96 y 103 del Código Civil. En el último, como medida provisional mientras se sustancia el procedimiento de nulidad, separación o divorcio. En los otros tres preceptos, se recoge como medida definitiva, cuando sean firmes las sentencias que resuelven dichos procedimientos.

La Ley 30/1981, de 7 de julio, supuso una regulación, que carecía de antecedentes, con respecto al régimen jurídico de la vivienda familiar en el Código Civil. El artículo 90 del Código Civil, en su redacción dada por la Ley 30/1981 de 7 de julio, establece la obligación de señalar en el convenio regulador acordado de mutuo acuerdo, a quién ha de serle atribuido el uso de la vivienda conyugal, con independencia de que sea propiedad de ambos cónyuges o de uno sólo de ellos.

Podría pensarse, dentro de cierta lógica(Domínguez 2008), que si uno de los cónyuges es el propietario del piso, debería ser éste quien fuera el destinatario del uso de la misma, pero el legislador entendió que el no titular también podía ser el titular del uso de la vivienda y ello se debe a que sobre la vivienda familiar tienen más importancia los intereses familiares que los particulares de cada cónyuge, ya que la vivienda familiar se ha configurado como un patrimonio al servicio de la familia

9 Nota de Prensa de la Oficina de Comunicación del Tribunal Supremo de 22 de mayo de 2013. 
como colectividad, como una especie de propiedad familiar que trasciende a los cónyuges, con independencia de que sea un bien privativo de uno de ellos.

El artículo 90 del Código Civil otorga relevancia al principio de autonomía de la voluntad, de forma que serán los cónyuges, a través de convenio regulador, quienes decidirán sobre el uso de la vivienda familiar, siempre que no sea perjudicial para los hijos o para uno de los cónyuges. Cuestión distinta es cuando estamos ante un proceso matrimonial contencioso, esto es, cuando no hay acuerdo entre las partes. En este caso, el criterio legal para la atribución de la vivienda existiendo hijos menores, viene de la dicción literal del artículo 96 del Código Civil:» En defecto de acuerdo de los cónyuges aprobado por el Juez, el uso de la vivienda familiar y de los objetos de uso ordinario en ella corresponde a los hijos y al cónyuge en cuya compañía queden".

Se produce así, una atribución automática que la mayoría de la doctrina y la jurisprudencia entienden como con carácter imperativo, ya que el uso de la vivienda familiar corresponde al cónyuge al que se confía la guardia y custodia de los hijos, basándose en que el interés más necesitado de protección en los procesos de ruptura matrimonial, siempre es el interés del menor. Esta norma, trata de favorecer la protección del interés de los hijos en el ambiente social y económico en el que han vivido, es decir continuar viviendo en el mismo domicilio. Esta atribución, obligará naturalmente a la salida de la vivienda familiar del cónyuge no custodio. Este criterio tan rígido en la atribución del uso del domicilio conyugal, lleva algún tiempo cuestionándose, como consecuencia de la "burbuja inmobiliaria" y por tanto, como consecuencia del aumento desmedido del precio de la vivienda(Pérez Villar 2011). En el IV Encuentro de Jueces y Abogados de Familia celebrado en Valencia en 2009, se propuso «5.- a) la reforma del artículo 96 del Código Civil de forma que se proceda a una distribución del uso de la vivienda familiar entre las partes con plazos máximos legales de asignación y posible alternancia en el uso, atendidas las circunstancias, siempre que así se garantice el derecho de los hijos a habitar una vivienda en su entorno habitual. $Y$ además que, b) hasta que se produzca la reforma del citado artículo, debe ser interpretado de forma que la asignación del uso exclusivo de la vivienda familiar sea un remedio subsidiario para los casos en que no se pueda garantizar de otro modo el derecho de habitación de los hijos. Y en todo caso, la asignación del uso exclusivo de la vivienda familiar, en los supuestos en que proceda, se haga siempre con carácter limitado».

Sin embargo, estas reivindicaciones chocan frontalmente con la doctrina emanada por nuestro Tribunal Supremo. Así, entre otras: Sentencias Tribunal Supremo (S TS): de 20 de mayo de 1990 (rec. 2113/1990. Ponente: Jaime Santos Briz), 14 de julio de 1994 (rec. 2384/1991. Ponente: Luis Martínez-Calcerrada Gómez), 1 de abril de 2011 (rec. 1456/2008. Ponente: Encarnación RocaTrías) y las más recientes SSTS de 114 de abril, 26 de abril, 21 de junio, 20 de septiembre de 2011 y 26 de abril de 2012, que establecen que «la citada norma no contiene ninguna limitación a la atri- 
bución del uso de la vivienda a los menores, mientras sigan siéndolo, porque el interés que se protege no es la propiedad de los bienes, sino los derechos que tiene el menor en una situación de crisis de la pareja». Optando así por la protección de los menores por encima de cualquier consideración patrimonial y sin limitación del derecho uso.

Otra cuestión a tener en cuenta, es ¿qué ocurre en los supuestos que el régimen establecido sea el de custodia compartida en los casos de ruptura matrimonial contenciosa? ¿Cómo se adjudica en estos supuestos el uso de la vivienda familiar?El artículo 96 del Código Civil, no contempla el caso en que se adopte como modelo la custodia compartida, ya que las previsiones que contempla son única y exclusivamente la atribución de la custodia a un solo progenitor, cuando se reparte la custodia de los distintos hijos entre padre y madre, o la atribución del uso al cónyuge más necesitado de protección cuando no convive ningún hijo en el domicilio familiar.

La modificación operada por la Ley 15/2005, que introdujo la posibilidad, como ya se ha dicho, del régimen de custodia compartida, aunque de forma excepcional, sin embargo no reformó los efectos económicos que este nuevo régimen podría producir entre las partes. Así, podemos decir, que el párrafo primero del artículo 96 del Código Civil no es aplicable en los supuestos de custodia compartida al no encontrarse los hijos en la compañía de uno solo de los progenitores. Estamos pues, ante un vacío legal, que obliga a acudir a Jueces y Tribunales a lo dispuesto en el párrafo segundo del citado precepto para los supuestos en que habiendo dos o más hijos comunes, uno o varios queden bajo la custodia de un progenitor y los restantes bajo la del otro: "el juez resolverá lo procedente" sobre el uso de la vivienda familiar y del mobiliario y ajuar existente en la misma. Pero esto es un precepto indeterminado que deja abierta cualquier posibilidad.

Puede señalarse que caben tres pronunciamientos judiciales(Marín García de Leonardo 2009): 1) que los hijos permanezcan en la vivienda familiar y sean los padres los que se desplacen en los periodos establecidos. En este caso, la vivienda se atribuye a los hijos y al progenitor que en cada momento los tenga en su custodia.2) que sean los hijos los que cambien de domicilio. Por lo que respecta a la vivienda habrá que atenderse al cónyuge más necesitado de protección, estableciéndose un límite de tiempo en su atribución. 3) que el Juez no asigne la vivienda a ninguno de los cónyuges, pudiendo proceder a la venta del mismo, con el fin de obtener cada uno los medios económicos necesarios para afrontar la custodia compartida.

¿Qué es lo que está ocurriendo en la práctica? Los Jueces y Tribunales a la hora de decidir sobre el uso de la vivienda familiar lo que tienen en cuenta es el interés más necesitado de protección, que en los conflictos de familia es el interés superior del menor. La Jurisprudencia está asegurando el derecho de habitación del menor, el cual puede quedar garantizado sin necesidad de hacer atribución del uso del domicilio familiar al menor y al progenitor con el que resida. Es más, la tendencia es que 
la asignación del uso exclusivo de la vivienda familiar debe ser un remedio subsidiario cuando no se pueda garantizar de otro modo(González del Pozo 2011).

Hay que tener en cuenta que generalmente la vivienda familiar es el bien más importante de una familia y que los dos progenitores que tienen la custodia compartida tienen el mismo derecho para la asignación del uso, por lo que las decisiones judiciales (generalmente de los Juzgados de Primera Instancia), están teniendo en cuenta principalmente(De la Iglesia Monje 2012), la capacidad económica de cada uno de los progenitores, cuestión que se resuelve rápidamente, si alguno de los progenitores puede habitar en una vivienda privativa, distinta de la familiar y cerca de ella. También puede solaparse lo anterior si es posible la venta de la vivienda familiar y la adquisición de dos viviendas cercanas. Y en último término, que es lo que se produce en la mayoría de las ocasiones, se asignará el uso de la vivienda familiar a los menores y coincidente y rotativamente a cada progenitor cuando tenga en ese momento la custodia compartida. Se producirá la asignación del uso de la vivienda familiar a uno solo de los cónyuges, en casos de custodia compartida, sólo cuando el cónyuge a quien se atribuya no pueda garantizar de otro modo el derecho de habitación de los hijos cuando los tenga en su compañía, siendo siempre tal atribución de carácter temporal y hasta la liquidación de la sociedad de gananciales, por un plazo máximo razonable ${ }^{10}$.

Como puede verse, mientras hay un vacío normativo en esta materia en la legislación estatal, sin embargo distintas Comunidades Autónomas han legislado sobre esto al igual que lo han hecho con la custodia compartida. Por ejemplo las Comunidades Autónomas de Aragón, Cataluña, Navarra y Valencia contemplan la custodia compartida como una opción preferente, otorgándole el uso de la vivienda familiar al cónyuge o progenitor más necesitado en la Ley de Cataluña (artículo 233-20.3 del Código Civil de Cataluña) y de Aragón ( artículo 81 del Código del Derecho Foral de Aragón), mientras que la legislación Navarra ( Ley Foral 3/2011 de 17 de marzo) nada dice sobre la atribución del uso de la vivienda familiar.

Siendo la legislación de Valencia (Ley 5/2011, de 1 de abril) la más extensa estableciendo en su artículo 6 que " 1 . A falta de pacto entre los progenitores en los casos de régimen de convivencia compartida, la preferencia en el uso de la vivienda familiar se atribuirá en función de lo que sea más conveniente para los hijos e hijas menores $y$, siempre que fuera compatible con ello, al progenitor que tuviera objetivamente mayores dificultades de acceso a otra vivienda. En el caso de atribuirse la

10 SAP Valencia, sección 10 de 11 de enero de 2012. Rec. 1220/2011 Ponente: María Pilar Manzana Laguarda; SAP Islas Baleares Sección 5 de 29 de junio de 2005. Rec. 2/2005. Ponente: Jaume Massanet I Moragues; Auto de 22 de junio de 2010, del Juzgado de Primera Instancia, numero 8 de Gijón, recurso 512/2010 Ponente Ángel Luis Campo Izquierdo, como muestra de abundantes sentencias en el sentido apuntado. 
vivienda familiar a uno de los progenitores, si ésta es privativa del otro progenitor o común de ambos, se fijará una compensación por la pérdida del uso y disposición de la misma a favor del progenitor titular o cotitular no adjudicatario teniendo en cuenta las rentas pagadas por alquileres de viviendas similares en la misma zona y las demás circunstancias concurrentes en el caso. Tal compensación podrá ser computada, en todo o en parte, como contribución a los gastos ordinarios con el consentimiento de quien tenga derecho a ella o en virtud de decisión judicial.2. Salvo acuerdo contrario entre los progenitores, en ningún caso se adjudicará una vivienda, aunque hubiera sido la residencia familiar habitual hasta el cese de la convivencia entre los progenitores, si es de carácter privativo del progenitor no adjudicatario o común de ambos y el progenitor al que se adjudica fuera titular de derechos sobre una vivienda que le faculten para ocuparla como tal residencia familiar. Si durante la ocupación como vivienda familiar de la perteneciente al otro progenitor o a ambos se incorporasen al patrimonio del cónyuge adjudicatario tales derechos, éste cesará en el uso de la vivienda familiar que ocupase hasta tal momento salvo acuerdo entre los progenitores y previa decisión judicial en su caso.3. En los supuestos de los dos apartados anteriores, la atribución de la vivienda tendrá carácter temporal y la autoridad judicial fijará el periodo máximo de dicho uso, sin perjuicio de que tal uso pueda cesar o modificarse, en virtud de decisión judicial, cuando concurran circunstancias que lo hagan innecesario o abusivo y perjudicial para el progenitor titular no adjudicatario».

Ante estas regulaciones previstas en las Comunidades Autónomas reseñadas, hay que decir, lo mismo que ya se ha dicho con respecto a la regulación autonómica de la custodia compartida. Se está produciendo una fuerte desigualdad por razón del lugar de residencia que hace necesario que sea corregido. Como dato, el $90 \%$ de las custodias de los hijos son otorgadas por los jueces a las madres tras un proceso de separación o divorcio y con ello, el uso de la vivienda familiar. Las custodias compartidas pactadas entre los progenitores o acordadas por la autoridad judicial no llegan a un $5 \%$ en el territorio nacional. Pero estos porcentajes varían sensiblemente en las Comunidades Autónomas as que han legislado sobre la materia, llegando a un $50 \%$ las sentencias dictadas que acogen la fórmula de la custodia compartida, y como vemos, ofreciendo distintas posibilidades sobre la atribución del uso de la vivienda familiar.

\section{Conclusiones}

Como se desprende de lo anterior, se hace necesaria una reforma legislativa, que ya ha sido anunciada por el actual Gobierno y que previsiblemente se va realizar en los próximos meses. Reforma que irá sin duda, encaminada a considerar la custodia compartida como una opción más, no excepcional ni preferente, sino como una de las opciones con las que cuentan las partes involucradas, siempre primando el interés del menor, con el fin de que los menores puedan mantener 
lazos afectivos y relaciones personales continuas con ambos progenitores en un plano de igualdad.

La realidad social actual dista mucho de la prevista en la Ley 30/1981, y la reforma operada por la Ley 15/2005 se presenta a todas luces insuficiente ya que no regula los efectos que produce la posibilidad de otorgar custodia compartida.En 2013, con unos modelos de familia tan distintos a la tradicional, a la que sirvió de base para la Ley 30/1981; con legislaciones autonómicas distintas entre sí y con la estatal, generando agravios comparativos dependiendo del lugar de residencia; con silencio normativo por parte de la legislación estatal cuando el Juez o Tribunal considere que la custodia compartida sea el modelo que mejor se adapte al caso concreto, dejando la solución a " el juez resolverá lo procedente» que es un precepto en blanco dejando abierta cualquier posibilidad; con proliferación de sentencias y de doctrina menor muy diferentes y con, en los últimos años, una abundante Jurisprudencia del Tribunal Supremo, que está acotando las distintas interpretaciones que hasta ahora se hacían por los Juzgados a la hora de atribuir el uso del domicilio familiar; es determinante la necesidad de reforma del artículo 96 del Código Civil y más en los tiempos de crisis actuales, teniendo en cuenta, que en la mayoría de las rupturas matrimoniales el patrimonio común es la vivienda familiar y que ésta puede quedar totalmente hipotecada cuando hay hijos menores.

No podemos cerrar los ojos a que, ante el panorama legislativo actual puedan surgir dosproblemas: que lo que realmente importa a la hora de solicitar la custodia compartida sea la atribución de la vivienda, o que por otra parte, haya una actitud en contra de la custodia compartida, perjudicando los derechos del menor, con la única finalidad de conseguir la atribución de la vivienda. Actuaciones sin duda muy cuestionables, pero que no por no deseadas debemos dejar de contemplar.La aplicación automática del artículo 96 del Código Civil está dando lugar a situaciones injustas. No sólo por falta de regulación expresa en los casos de custodia compartida, sino también por el automatismo legal de otorgar la atribución del uso de la vivienda a los menores en caso de custodia exclusiva. $Y$ hay que buscar soluciones, que respetando el interés de los menores a tener una vivienda digna donde habitar, se concilien con la dignidad de vida de ambos progenitores.

La protección del menor, puede generar en números supuestos la asfixia económica de sus progenitores o de uno de ellos, que sin lugar a duda también pone en peligro el bien supremo al que debe atenderse cuál es la protección del menor. La necesidad en numerosos supuestos de tener tres viviendas donde habitar ( la común donde reside el menor y una por cada progenitor para residir durante los periodos de tiempo que no ejerzan la custodia) con un alto coste económico, los gastos de mantenimiento de éstas, los alimentos a que ambas partes están obligados, los problemas que se derivan de la gestión de un espacio común no sólo económicamente sino también emocionalmente, en un momento, en que por muy buenas que sean las relaciones entre ambos progenitores, no podemos olvidar que han puesto fin a 
su relación y no han sido capaces de llegar a un acuerdo para regular sus relaciones, en un momento en que se encuentran en un proceso contencioso para la disolución de su relación.

Todo esto hace que se produzcan paradojas de la propia normativa y que el bien supremo que protege, interés del menor, también entre en peligro en la medida de los recursos económicos de sus padres progenitores. Por ello, debería procederse a una regulación que pondere todas estas cuestiones teniendo en cuenta la capacidad económica de cada progenitor, la titularidad de la vivienda familiar, la situación laboral y personal de cada uno de los cónyuges, e incluso a tender a la posibilidad de permitir la venta de la vivienda familiar. Pero todo esto no tendrá realmente la finalidad perseguida, si no se apela a las actitudes conciliadoras de ambos progenitores.

\section{5.- Bibliografía}

Aguilera Arilla, M.J., González, Yanci, M. P. 2003. «El divorcio en España tras 22 años de su legalización». Anales de Geografía de la Universidad Complutense 23, 117-130.

Alascio Carrasco, L., Marín García, I. 2007. "Juntos pero no revueltos: la custodia compartida en el nuevo art.92 CC». In Dret. Revista para el análisis del derecho 3, 2-23.

Alascio Carrasco, L. 2011. "La excepcionalidad de la custodias compartida impuesta». In Dret. Revista para el análisis del derecho 2, 1-26.

Álvarez García, M.D. 2011. "Custodia Compartida". Diario La Ley. Revista n 61, Tercer Trimestre.

Campuzano Tomé, H. 2005. La custodia compartida. Doctrina Jurisprudencial de las Audiencias Provinciales. Pamplona: Aranzadi Civitas.

Catalán Frías, M. J. 2011. La custodia compartida. Valencia: Tirant lo Blanch.

Carreras, A., Taforell, X. 2005. Estadísticas históricas de España: siglos XIX-XX. Bilbao: Fundación BBVA.

De la Iglesia Monje, M. I. 2012. "Custodia compartida y el derecho de uso de la vivienda familiar. Análisis Jurisprudencial». Revista Criticade Derecho Inmobiliario, 732, 22352478.

Del Fresno García, M. 2011. Retos para la intervención social con familias en el siglo XXI: consumo, ocio, cultura, tecnología e hijos. Madrid: Trotta.

Delgado del Río, G. 2010. La guarda compartida: opción preferente. Pamplona: Aranzadi Civitas.

Delgado Pérez, M. 1993. "Cambios recientes en el proceso de formación de la familia". Revista Española de Investigaciones Sociológicas 64, 123-153.

Diario de Sesiones (DS). 2012. Congreso de los Diputados. Comisiones, n²5 de 25/01/2012.

Domínguez Martínez, P. 2008. «Definición y atribución del domicilio familiar». Facultad de Ciencias Sociales de Cuenca. Seminario permanente de ciencias sociales. Documento de trabajo 2008/5. 
El Huffington Post. 2012. "Divorcios en España: un 24\% menos que antes de la crisis" (en www.huffingtonpost.es/2012/09/13)

Quílez, R. 2013. "Gallardón equiparará por ley la custodia compartida y monoparental". El Mundo del siglo XXI, 25/05/2013 (http://www.elmundo.es/accesible/elmundo/2013/05/20/espana/1369051358.html)

González del Pozo, J. P. 2009. «El derecho de uso de la vivienda familiar en los supuestos de guarda y custodia compartida». Diario La Ley. Revista número 60, 12968/2009.

González Moreno, B. 2009. "El principio de igualdad en el ámbito del Derecho de Familia: La custodia compartida". Pp. 122-140, en Políticas de igualdad y Derechos Fundamentales, coordinado por González Moreno B. Valencia: Tirant lo Blanch.

Herrera de las Heras, R. 2011. "Sobre la necesidad de una nueva regulación de la guarda y custodia". Actualidad Civil, 10 de 31 de mayo de 2011.

INE. 2012. Estadística de nulidades, separaciones y divorcios. Madrid: INE.

Ivars Ruiz, J. 2007. "La custodia compartida tras la reforma del Código Civil". Revista Internauta de Práctica Jurídica, 19.

Marín García Leonardo, T. 2009. "Problemas que genera la actual regulación de la gaurda y custodia compartida en el proceso contencioso". Diario La Ley, n 7105 de 2 de febrero de 2009. La Ley 40228/2008.

Martín Meléndez, M.T. 2005.Criterios de atribución del uso de la vivienda familiar en las crisis matrimoniales: Teoría y práctica Jurisprudencial. Pamplona: Civitas - Aranzadi.

Palacios, J., Hidalgo, M. U., Moreno, M. C. 1998. "Familia y vida cotidiana." Pp. 145-156, en Familia y Desarrollo Humano, coordinado por M. J. Rodrigo y J. Palacios (coords.). Madrid: Alianza Editorial.

Pérez Galván, M. 2011. "Vivienda familiar y crisis de pareja. Atribución del derecho de uso." Diario La Ley. Revista n 7711.7 de octubre 2011. La Ley 15802/2011.

Pérez Galván, M. 2009. "Problemas prácticos en el régimen de guarda y custodia compartida". Diario La Ley, de 29 de Junio de 2009, n 7206.

Rivera Álvarez, J. M. 2005. "La custodia compartida: génesisi del nuevo art. 92 del Código Civil". Cuadernos de Trabajo Social 18, 137-162.

Simon, M. I., Iriana, B., González, M. M. 1998. "Vida familiar y representaciones de la familia". Pp. 198-201 en Familia y Desarrollo Humano, coordinado por M. J. Rodrigo y J. Palacios. Madrid: Alianza Editorial. 